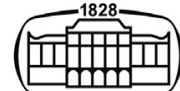

AKADÉMIAI KIADÓ

Journal of Behavioral Addictions

9 (2020) 2, 469-482

DOI:

$10.1556 / 2006.2020 .00031$

(c) 2020 The Author(s)

\section{FULL-LENGTH REPORT}

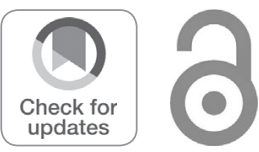

\title{
How have excessive electronics devices and Internet uses been concerned? Implications for global research agenda from a bibliometric analysis
}

BACH XUAN TRAN ${ }^{1,2 *} \odot$, GIANG HAI HA ${ }^{3,4}$, GIANG THU VU ${ }^{5}$, CHI LINH HOANG ${ }^{6}$, SON HOANG NGUYEN ${ }^{7}$, CUONG TAT NGUYEN ${ }^{3,4}$, CARL. A. LATKIN ${ }^{2}$, WILSON WS TAM ${ }^{5,8}$, CYRUS S. H. $\mathrm{HO}^{9}$ and ROGER C. M. $\mathrm{HO}^{6,10,11}$

${ }^{1}$ Institute for Preventive Medicine and Public Health, Hanoi Medical University, Hanoi, Viet Nam

${ }^{2}$ Bloomberg School of Public Health, Johns Hopkins University, Baltimore, MD, USA

${ }^{3}$ Institute for Global Health Innovations, Duy Tan University, Da Nang, Viet Nam

${ }^{4}$ Faculty of Pharmacy, Duy Tan University, Da Nang, 550000, Vietnam

${ }^{5}$ Center of Excellence in Evidence-based Medicine, Nguyen Tat Thanh University, Ho Chi Minh City, Viet Nam

${ }^{6}$ Center of Excellence in Behavioral Medicine, Nguyen Tat Thanh University, Ho Chi Minh City, Viet Nam

${ }^{7}$ Center of Excellence in Health Services and System Research, Nguyen Tat Thanh University, Ho Chi Minh City, Viet Nam

${ }^{8}$ Alice Lee Centre for Nursing Studies, Yong Loo Lin School of Medicine, National University of Singapore, Singapore

${ }^{9}$ Department of Psychological Medicine, National University Hospital, Singapore

${ }^{10}$ Department of Psychological Medicine, Yong Loo Lin School of Medicine, National University of Singapore, Singapore

${ }^{11}$ Institute for Health Innovation and Technology (iHealthtech), National University of Singapore, 117599, Singapore

Received: March 01, 2019 • Revised manuscript received: September 30, 2019 • Accepted: May 04, 2020 • Published online: July 7, 2020

\section{ABSTRACT}

Background and aims: Excessive use of electronic devices has become a major global problem. However, little is known about the development and current landscape of research concerning this field. This study aimed at exploring the overall publication trend and topics of research on the overuse of electronic devices and the Internet from 1971 to 2017. Methods: We systematically searched the Web of Science (WoS) and Scopus databases for published articles on the excessive use of electronic devices and the Internet. Data regarding the publication volume, international collaborations, and geographical locations were analyzed by bibliometrics analysis. Latent Dirichlet Allocation (LDA) was undertaken to categorize publications into different research topics. Results: A total of 2,276 papers from the WOS and 600 papers from the Scopus were included. We found a dramatic increase in the number of scientific papers towards addiction to electronic devices and the Internet. The United State led in all publication parameters including the total number of papers and total citations. China, Korea and Taiwan were among the most prolific countries/regions. Smartphone addiction was the main concern, and the relationship between the overuse of electronic devices and the Internet and mental health issues have been highlighted. On the other hand, our study found a limited appearance of discussion on effective treatment and intervention. Discussion and Conclusion: The findings of this study call for more national and international cooperation in evaluating and intervening addiction to electronic devices and the Internet to gather more knowledge about this phenomenon and evaluate the effectiveness of treatment. 


\section{KEYWORDS}

bibliometrics, PIU, Internet addiction, gambling disorder, gaming disorder, text mining

\section{INTRODUCTION}

The drastic advancement of the Internet has dramatically changed the lives of people worldwide in both positive and negative ways. With over 2.5 billion users estimated by the end of 2019 (Statista), the Internet has undeniably significant role in everyday life (Deetjen \& Powell, 2016; Jung et al., 2014); however, it has also led to issues that have not existed before the era of the Internet, such as excessive Internet use or electric-related addictions. Problematic Internet use (PIU) has been documented as a common phenomenon in both developed and developing countries, causing health and social problems. Previous studies conducted in some European countries have found the prevalence of PIU to be between $0.7 \%$, and 18.3\% (Bakken, Wenzel, Gotestam, Johansson, \& Oren, 2009; Billieux et al., 2013). In Asia, the prevalence of PIU was reported to vary from $2 \%$ to $21.2 \%$ (Ha et al., 2006; Ko et al., 2005; Mak et al., 2014; Mythily, Qiu, \& Winslow, 2008; Tran et al., 2017; Wu, Chen, Tong, Yu, \& Lau, 2018). A recent study by Cheng et al. in 2014 showed the varying prevalence of PIU in 31 countries across regions: $8.0 \%$ in the United States, $7.1 \%$ in Asian countries, and $10.9 \%$ in the Middle East countries (Cheng \& Li, 2014). Existing literature has also provided evidence indicating that age and gender did not account for the high heterogeneity in the prevalence of PIU (Zhang, Lim, Lee, \& Ho, 2018).

The kind of activity that can be classified as excessive or pathological use of computers and the Internet has been the topic of discussion in the last few decades, along with the development of computers and the Internet. In the United States, the first publication on the topic was by Young et al. in 1996 which reported as a case of a woman with email addiction (Young, 1996), followed by the first seminar on Internet Addiction (Young, 1998). In Europe, Griffiths (1995) first described "technological addiction" as a "nonchemical addiction involving human-machine interaction", followed by a general paper on the Internet and Internet gambling addiction (Griffiths, 1995, 1996). In 1980, pathological gambling was first added to the Diagnosis and Statistical Manual of Mental Disorders (DSM), which was classified as an impulse control disorder. After that, in DSM-V in 2015, pathological gambling was renamed to the "Gambling disorder", and re-classified as "Substance-Related and Addictive Disorders" (Rennert et al., 2014).

In this study, we used the definition and diagnosis of the International Classification of Diseases (ICD-11), which includes gambling disorder (pathological gambling in ICD10) and gaming disorder as two diagnostic categories (Fauth-Bühler, Mann, \& Potenza, 2017). The inclusion of gaming disorder in the ICD-11 and the DSM-5 has raised some arguments. A number of researchers call for exclusion due to, among other reasons, the lack of general agreement regarding the symptoms or predictions of the health issue (Aarseth et al., 2017) that makes it insufficient to be regarded as a mental health disorder (Dullur \& Starcevic, 2018). On the other hand, some supported the inclusion (Griffiths, Király, Pontes, \& Demetrovics, 2015; Griffiths et al., 2016; King, Delfabbro, Doh, et al., 2018a; King, Delfabbro, Potenza, et al., 2018b; Kiraly \& Demetrovics, 2017). Thus, the inclusion of GD in ICD and DSM could be considered a common starting point for researchers in upcoming research and monitoring (Kiraly \& Demetrovics, 2017).

Despite having received seemingly significant attention, PIU has yet to have a formal definition that was agreed among academia. To date, a range of different definitions has been given to this phenomenon, notably compulsive computer use (Black, Belsare, \& Schlosser, 1999), Internet dependency (Sherer, 1997), pathological Internet use (Davis, 2001), and Internet addiction (Young, 1998). Shapira et al. characterized PIU as an inability to control Internet use (Shapira et al., 2003), while Black et al. indicated that compulsive computer use meant psychiatric illness (Black et al., 1999). Davis (2001) proposes a theoretical cognitive and behavioral model of pathological Internet use (PIU), identifying the PIU into two categories: Generalized Problematic Internet Use (GPIU) and Specific Problematic Internet Use (SPIU) (Davis, 2001). Alternatively, Young (1999) divided PIU into five subtypes: cyber-sexual addiction, cyber-relationship addiction, net compulsions, information overload, and computer addiction (Young, 1999).

Literature highlighted that excessive Internet use could lead to a range of psychiatric disorder including attentiondeficit/hyperactivity disorder (ADHD) (Yen et al., 2017), conduct problems (El Asam, Samara, \& Terry, 2019), borderline personality disorder (Lu et al., 2017), impulsivity (Zhang et al., 2015), generalized anxiety disorder (Wang et al., 2017), social anxiety (Ko, Yen, Yen, Chen, \& Chen, 2012), premenstrual dysmorphic disorder (Ko et al., 2014), anhedonia (Guillot et al., 2016), depression (Chou et al., 2015), suicidality (Harris, Starcevic, Ma, Zhang, \& Aboujaoude, 2017; Lin et al., 2014) and lifestyle problems such as sleeping disturbance (Park et al., 2018; Zhang et al., 2017), harmful alcohol use (Ko et al., 2009), decreased time spent on exercising (Dang et al., 2018; Kojima et al., 2019) and schizophrenia (Lee et al., 2018).

Several systematic reviews and meta-analyses have been conducted in the field of Internet addiction and problematic Internet use (Anderson, Steen, \& Stavropoulos, 2017; Breslau, Aharoni, Pedersen, \& Miller, 2015; Kuss \& LopezFernandez, 2016). Although these studies provided insights into treatment to people with Internet-addictions and Internet Gaming Disorder (Kuss \& Lopez-Fernandez, 2016) or PIU behaviors among adolescents (Anderson et al., 2017), their focuses were on specific topics without allowing for comparison between papers of different topics and over time. Meanwhile, when attempting to obtain a broad view of research development concerning certain topics, researchers 
have generally adopted bibliometrics analytic. The limitation of bibliometrics, however, has been in its lack of power to discover the landscape of research topics hidden in the publications. In this study, we attempted to overcome such limitations by combining bibliometrics and text mining (of titles and abstracts) of publications on the overuse of electronic devices and the Internet. Findings of this study can potentially support the development of the research agenda in this field, policy formulation and the design and implementation of prevention approaches for PIU from an international perspective (King, Delfabbro, Doh, et al., 2018a).

\section{METHODS}

\section{Data source}

We obtained research publications focused on all forms of addiction involving the Internet and electronics. The Web of Science (WOS) and Scopus are the two most massive databases with various research fields (Guz \& Rushchitsky, 2009). Meanwhile, PubMed covers mostly biomedical literature (Kokol \& Vošner, 2018), PsycINFO focuses on behavioral science and mental health (EBSCO). In this kind of study, we wanted to explore the excessive use of electronic devices and the Internet in all research areas. Therefore, we decided to collect data from the two online databases: WOS and Scopus. Our aims are 1) focusing on all forms of electronic and Internet addiction published from inception to December 31st, 2017 in a peer-reviewed journal; and 2) comparing the results of the same set of keywords between the two databases. The searching process was conducted in August 2018, thus, we decided to exclude the 2018 articles because any capture from that period forward would include incomplete bibliometric data for that year. We did not include gray literature, conference proceedings, or books/ book chapters in our analysis. For filter processing, articles written in any language other than English were excluded.

\section{Search strategy}

First, the literature from the WOS and Scopus were retrieved using a developed set of search terms, focused on five subtypes of Internet addiction: 1) Cybersex Addiction, 2) Cyber Relationships, 3) Computer Addiction (Game online addiction), 4) Net compulsion, 5) Informational overload. Besides, to qualify other types of addiction related to electronic devices, we applied in our search query 6) Mobile phone overuse, 7) Game machine addict, 8) Gambling machine addiction. Synonyms for search terms were designed by our team. The following search terms were combined with the above keywords, and their synonyms: "excessive', "problematic', "compulsive", and "addictive" (see Tables S1 and S2 Supplementary).

Secondly, we excluded 1) articles published on January 1st, 2018 onwards, 2) unrelated document types, such as book chapters, and conference proceedings, 3) items with anonymous authors in WOS or "undefined" fields in subject areas, country field, or author field in Scopus and 4) studies written in any language other than English.

After running our search with the above criteria, we downloaded 2,732 papers from WOS and 614 papers from Scopus. Two team members read the abstract, and keywords to filter the unrelated documents. The two other team members verified the data to minimize the errors. All potential discrepancies were resolved via discussion.

After filtering, 2,276 papers from WOS and 600 papers from Scopus were downloaded for further analysis. Each article included the following information: document title, authors, author address, publication year, author keywords, research area, source title, and times of citation. All the data were downloaded in text format and stored in MS Microsoft Excel (see Figs. S1 and S2 Supplementary).

\section{Bibliometric analysis}

We performed this bibliometric analysis by using the bibliometric package in R (Aria \& Cuccurullo, 2017). The metadata in the WOS and Scopus was used to calculate and rank authors' articles, country production and collaborations, and journal publication.

Country production in $\mathrm{R}$ was defined by the corresponding author's country. The number of publications was used as an indicator of research productivity. For author production, we applied the number of papers and h-index to identify the contribution of that author to the research field (Opthof \& Wilde, 2009). In the case of collaborative papers, we applied full counting for the geographical distribution of citations and country collaborations network (PerianesRodriguez, Waltman, \& van Eck, 2016).

The general characteristic of the dataset including journals, countries distributions, and author keywords identified the changes in the research trend of this topic.

Visualization, which might be labeled as a part of visual analytics, has been considered "a new research discipline" in the last 20 years. For the large volumes of data such as bibliographic data, visualization is an effective way to analyze information from the abstracts and help the analysists to make decisions based on the data (Yu \& Hayes, 2018). We then visualized the collaboration of the most productive countries using VOSviewer software (http:// www.vosviewer.com/) to 1) create visualization maps representing the contributions, and collaboration efforts of countries in the two databases, and 2) visually describe research efforts directed towards interrelated research subjects by mapping out terms in the title and abstracts. In the country cooperation network, the closer two countries are located to each other, the stronger their collaboration. In the network visualization, items are represented by their label and by a circle. The size of the label and the circle of an item is determined by the weight of the item. The higher the weight of an item, the larger the label and the circle of the item. The technique using for constructing co-occurrence networks of terms extracted from title and abstracts of publications can be found elsewhere (van Eck \& Waltman, 2011; van Eck, Waltman, Dekker, \& van den Berg, 2010). 


\section{Analysis of abstracts/titles}

To discover the hidden terms in the titles and abstracts, we applied a text-mining tool: topic modeling technique. Specifically, we chose Latent Dirichlet allocation (LDA) which is one of the most widely used and helpful methods to classify papers into similar topics (Chen et al., 2017; Li, Rapkin, Atkinson, Schofield, \& Bochner, 2019; Valle, Albuquerque, Zhao, Barberan, \& Fletcher Jr, 2018; Wang, Joo, \& Lu, 2014). LDA used a probabilistic model of the text data and groups different documents into topics. Since authors would use similar words for a same topic, LDA would use co-occurrences of words to identify each topic as a probability distribution over words (Schwarz, 2018).

We decided to visualize data (title, and abstracts) using VOSviewer, a distance-based visualization of bibliometric networks, to explore high-quality information. Visualizing networks has received attention form scientists. It has been a powerful method to identify the hidden topics of a large dataset (Van Eck \& Waltman, 2014). The papers were then classified into four research areas: co-comorbidity; methods used to identify Internet addiction prevalence; the impact of IA and the treatment; the main subject of studies.

LDA has been considered a productive technique for modeling text data, including research articles (Jelodar et al., 2019). Besides, the text mining function of VOSviewer, which here we applied to titles and abstracts of the selected publication, offers a powerful approach to analyze and visualize topic mapping scientific literature (Van Eck \& Waltman, 2014). While VOSviewer evaluates the co-occurrence of the terms to conduct the clusters for a quick and clear overview of the research topics, LDA provides a deeper analysis of the terms' meaning and categorizes the papers into different groups of research topics (Van Eck \& Waltman, 2014). In order to cross-check and confirm the results of the two methods as well as demonstrate a multi-level analysis for the research terms, both techniques were used in this study.

\section{RESULTS}

\section{The quantity of literature and the growth trend}

Fig. 1 summarizes characteristics of the research output of the current excessive use of electronic devices and the Internet during the period from 1971 to 2017. Although the number of papers in the WOS was more than that in Scopus, both showed a similar trend over the study period. The annual total of publication, total citation, and citation per article author, the number of countries, and the average author per paper publishing literature related to the overuse of electronic devices and the Internet rose significantly in both databases (Fig. 2, Fig. S3 and Table S3 Supplementary). The first item was published in 1971 but rose to 469 in 2011 in WOS, and 102 in Scopus. In both datasets, the earliest reports on this aspect dated back to 1971 when Levine and Stephens expressed their concern with addiction to street games (Levine \& Stephens, 1971). Raubolt and Bratter mentioned group treatment applying for games addicts play in his 1974 research paper "Games addicts play: Implications for group treatment". Besides, the average number of the author in 1971 was two, this figure significantly increased double by 2017 . The article with the highest number of authors (31) in WOS, published in Addiction (2012), provided the prevalence of PIU (4.4\%) among adolescents in European countries (Durkee et al., 2012). Meanwhile, the article with the most authors (14) in Scopus, published in Psychiatry Research (2016), identified the association between problematic alcohol and PIU among adolescents due to common psychopathological factors (Wartberg et al., 2016). The number of countries that involved in this study rose speedily during the period, starting with a minimum of 1 country in 1971 for both datasets, and increased to a maximum of 63 in 2017 (WOS) and 27 countries in 2016 (Scopus) (see Table S4 in Supplementary). The total citation of WOS increased dramatically while that of Scopus rose slightly. The average citation per article per year shows the impact of a publication. The papers in the year 2004 (WOS dataset) and the papers in the year 2007 (Scopus dataset) had the highest impact with the average citation per article per year were 17.93 and 11.86 , respectively.

\section{Journals, and categories distribution}

Based on the classification of the research areas in WOS and Scopus, we selected four categories with the highest number of publications from 2000-2017 (Fig. S4a and b Supplementary). The number of papers per category presented a continued growth, which indicates that these research topics have been steadily emerging in various categories. The four most common categories throughout 17 years in WOS dataset were: Psychology, Psychiatry, Substance abuse and Neurosciences \& Neurology. In the same line with WOS, Psychology and Neurosciences \& Neurology were in the top four, the others were Medicine and Computer Science.

Fig. 3 shows the number of papers and citations attributing to the 15 most prolific journals, which included productivity and the ranking of the journal. In total, 2,276 articles were published in 666 journals (WOS), 600 articles were published in 261 journals (Scopus). Based on the total number of papers and its growth trend, we defined a popular journal as a journal that contributed at least ten articles in the field. As a result, 633 (95\%) journals in WOS dataset and 253 (96\%) journals in the Scopus data, published less than ten articles. As the leader of this research topic, the Computers in Human Behavior published the most research papers $(264 ; 11.6 \%$ in WOS, and $87 ; 14.5 \%$ in Scopus), followed by Cyberpsychology, Behavior, and Social Networking (WOS: 124; 5.5\%; Scopus: 87; 5.8\%); Journal of Behavioral Addictions (WOS: 87; 3.8\%); Addictive Behavior (17; 2.8\%). Throughout the research field, the highest impact factor (IF) journal was Addiction (Scopus; 5.953), and Journal of behavioral addictions (3.628; WOS). In WOS database, the most frequently cited journal was Cyberpsychology and Behavior with a total of 8,175 citations during 


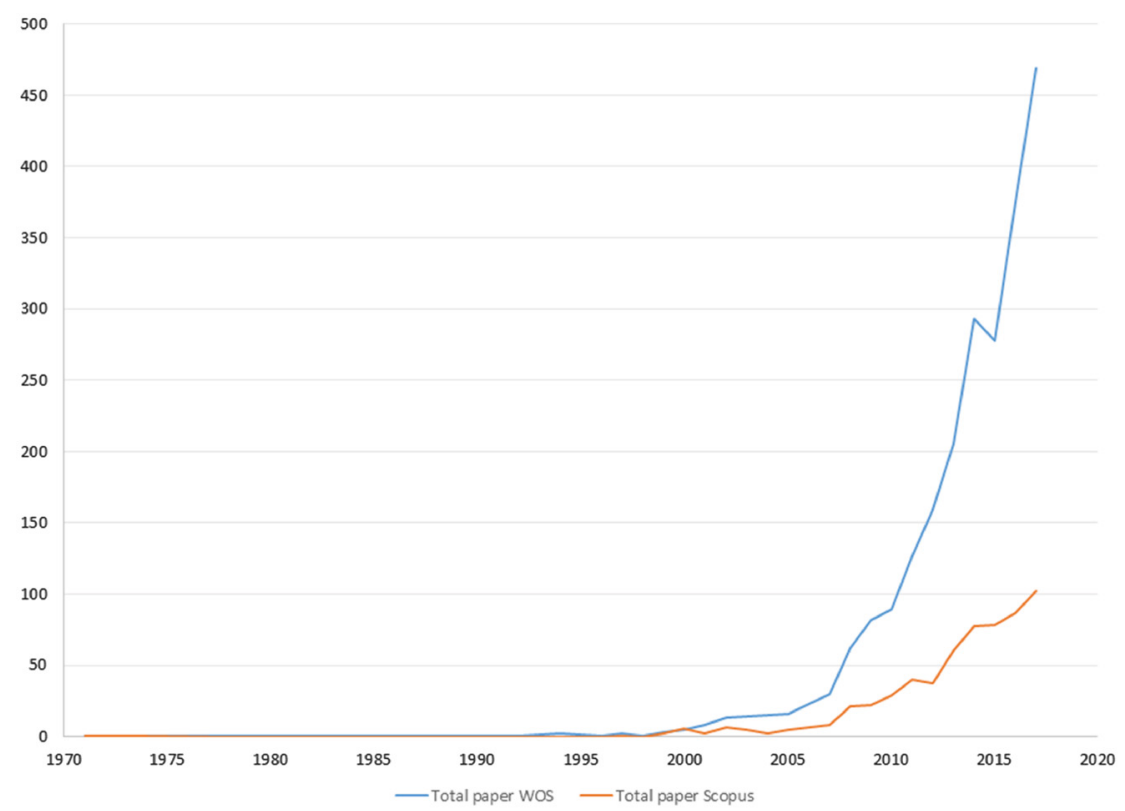

Fig. 1. Number of publications in WoS and Scopus

Total citations WOS

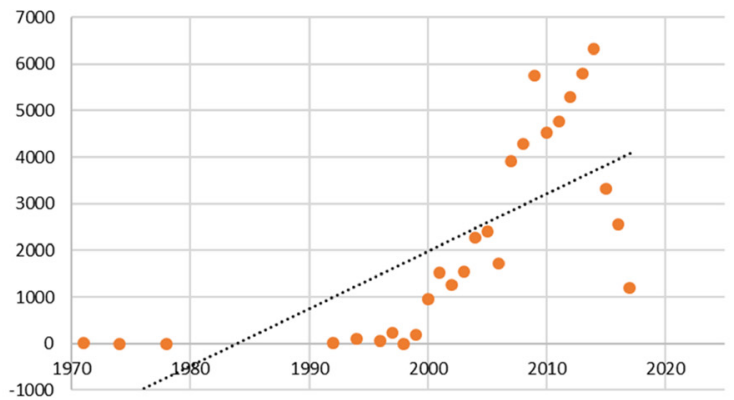

Citation per article WOS

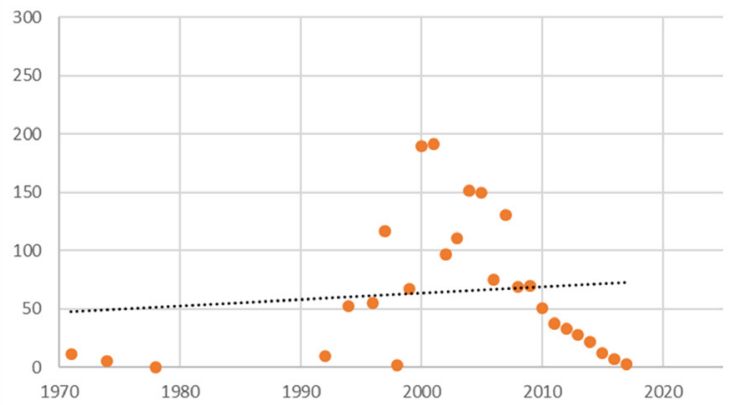

Total citations Scopus

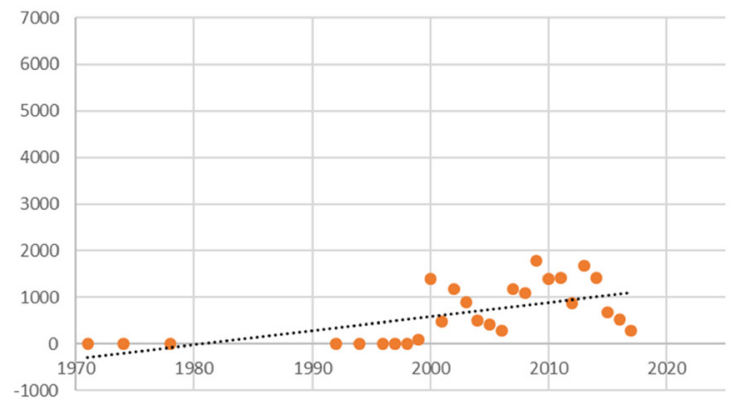

Citation per article Scopus

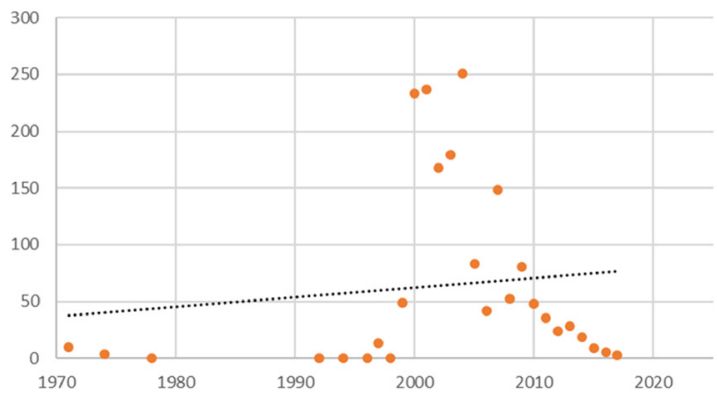

Fig. 2. Total number of citations and citations per article of WoS, and Scopus

the given period, and it ranked first with the average citation score (113.54) among the core journals. In Scopus, Computers in Human Behavior had the highest number of total citations, however, the highest averagecitation per article was Cyberpsychology and Behavir (138.96). However, the average citation per article of Computer in Human Behavior was higher than that of Addiction while its IF was slightly lower than that of Addiction (5.953).
For global collaboration, the top 15 countries/regions were ranked by productivity, total citations, and global cooperation in articles (see Table S4 Supplementary). The number of papers and total citations in WOS was higher than those of Scopus. Some countries in North America countries, Europe (WOS: 10 countries, Scopus: 9 countries), Asia (WOS: 7 countries, Scopus: 8 countries), as well as Australia were in the top 20 countries based on the number 


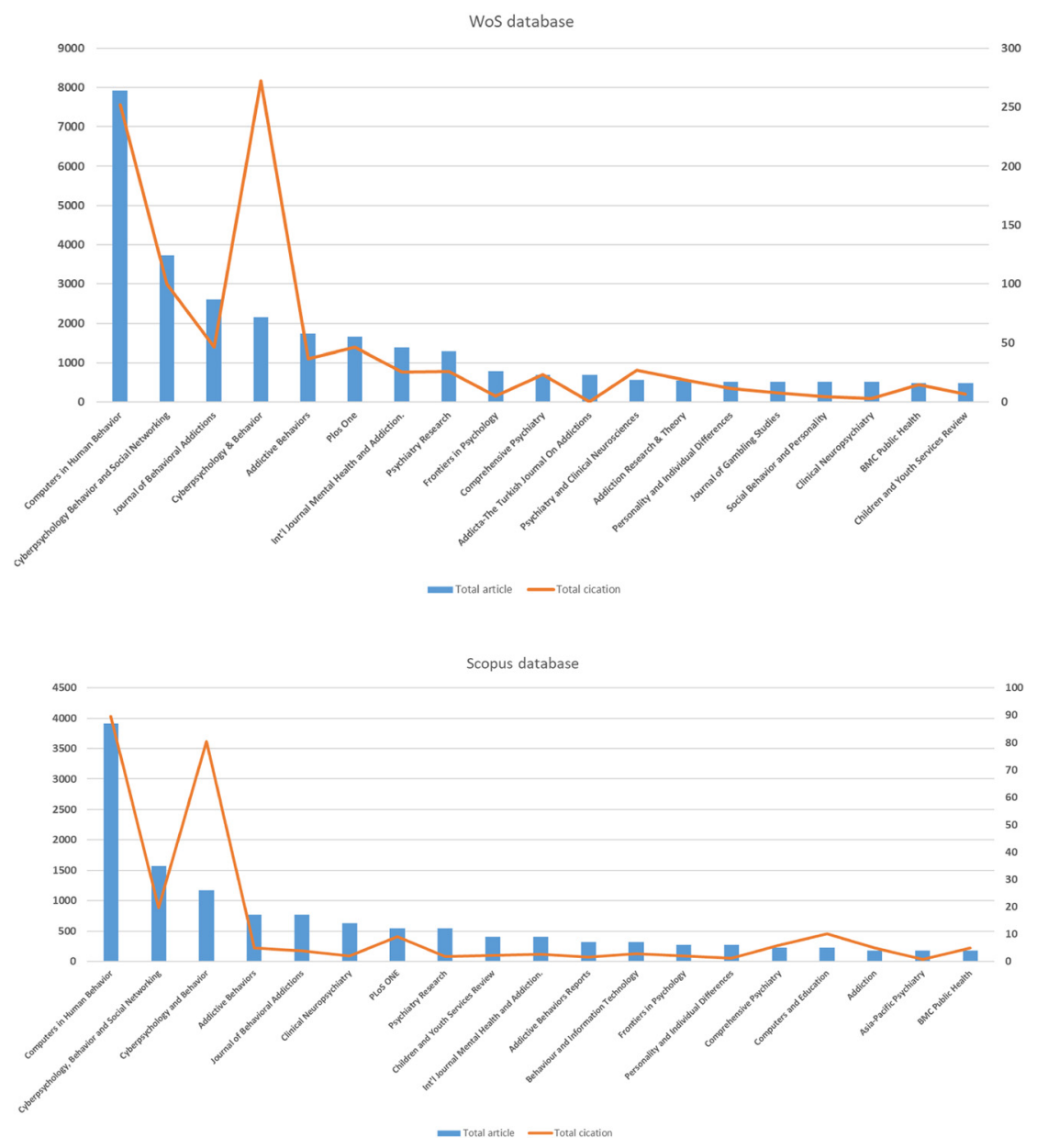

Fig. 3. Most active journals in the field of excessive electronic devices and Internet uses (based on the total number of articles and total citations)

of publications. Surprisingly, there was no representative country from Africa among the top 25 of the most productive countries in both databases. The top 20 productive countries contributed $67 \%$ (Scopus), and $86.4 \%$ (WOS) of total articles. Furthermore, 20.4\% (WOS), and 17.5\% (Scopus) were global articles, which indicated these countries having great cooperation in this research field. Interestingly, two Asian countries (China, and South Korea) appeared in the top five of the most prolific countries, which accounted for $21.1 \%$ (WOS), and $13 \%$ (Scopus) in the total number of publications. The top 5 of the most prolific countries were the USA (WOS: 373, Scopus: 88), China (WOS: 283, Scopus: 34), Korea (WOS: 198, Scopus: 44), Turkey (WOS: 158, Scopus: 26), and United Kingdom (WOS: 140, Scopus: 30). In the WOS dataset, six countries published papers only with the cooperation to other countries (Qatar, Scotland, Macedonia, Slovenia, United Arab Emirates, and Vietnam) meanwhile 18 countries only had domestic cooperation (South Africa, Cyprus, Croatia, Kuwait, Bangladesh, Denmark, Estonia, Peru, Romania, Thailand, Chile, Egypt, Indonesia, Iraq, Lithuania, Mexico, Tanzania, Tunisia). In both databases, the US ranked first in terms of total citations (WOS: 14,456, Scopus: 5,595) while Czech Republic (Scopus), and Poland (WOS) had the lowest total citation among the top 20 most prolific countries (see Table S3 Supplementary).

Fig. 4 shows the international collaboration of 69 countries (WOS) and 46 countries (Scopus). The size of nodes is proportional to the relative contribution based on the number of papers, and the line thickness represents the strength of international collaboration. The United States was the largest contributor in this field, followed by China and South Korea.

Based on the WOS data, the United States closely collaborated with Canada, England, and Australia. The clusters of collaboration were also seen among countries located in Asia, and Europe. For instance, South Korea, China, Taiwan, Japan, and Malaysia were proximally located with one another, indicating the Asian collaboration. Clustering was also seen between Switzerland, Belgium, Poland, Israel, France, and Brazil.

Based on the Scopus data, there was the main group which included seven countries having the closest collaboration: the US, South Korean, Turkey, Malaysia, Singapore, Japan, the Philippines. Some of the European countries (Switzerland, Belgium, Poland, France) formed research collaboration with Canada and Israel. Northern European countries (Italy and Portugal) and Southern European 


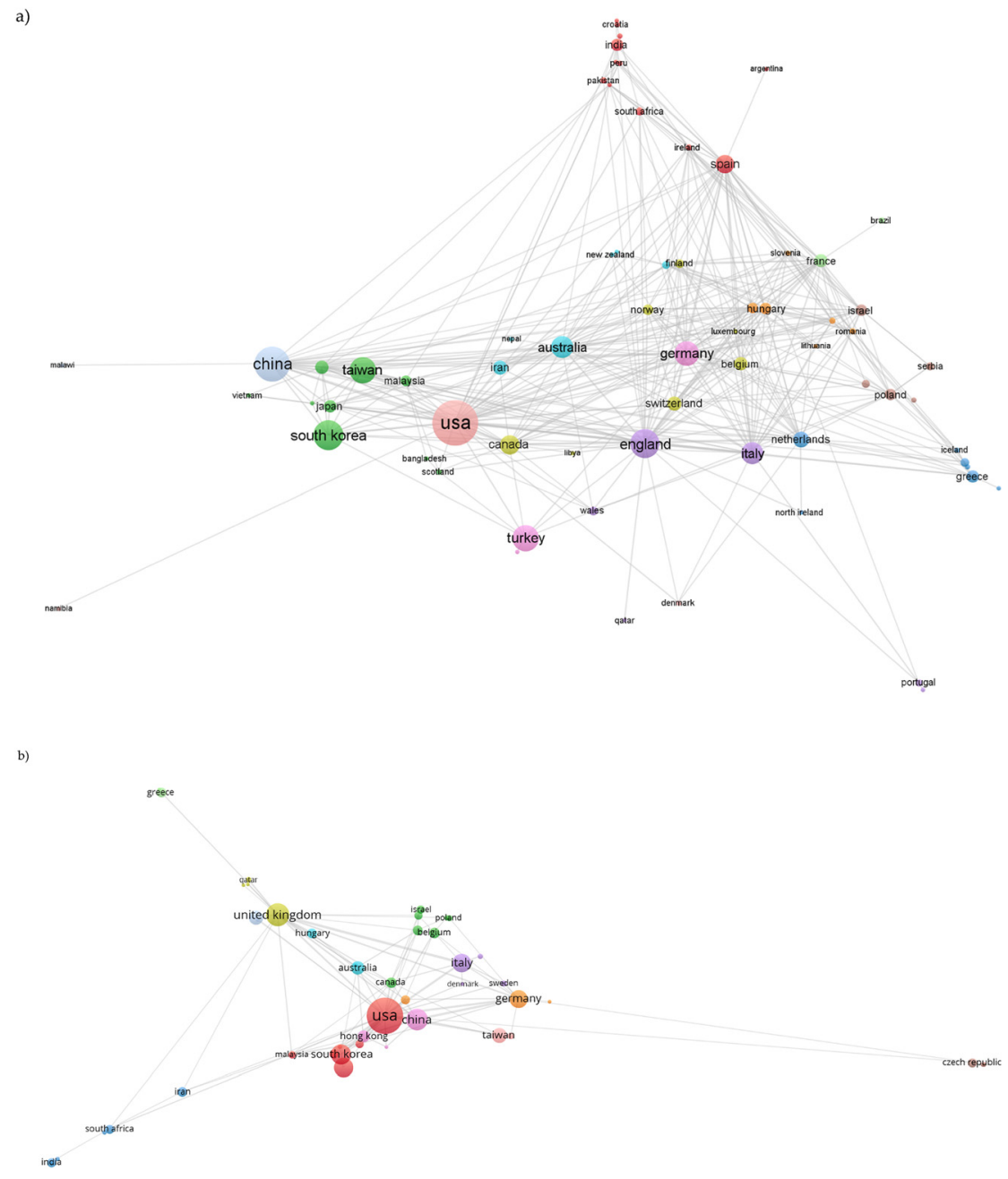

Fig. 4. (a). The global network among countries in WOS. (b). The global network among countries in Scopus

countries (Denmark and Sweden) formed a strong collaboration.

Fig. 2 shows the number of citations and citations per article. Those figures in the WOS database were more than those in Scopus. In both databases, it shows that almost onethird of all citations belonged to papers published by researchers in the USA which is the country that contributed the highest number of papers (see Fig. S1 Supplementary). Other significant contributors including researchers from China, Taiwan, and South Korea but less citation impact as compared to papers published by researchers in the USA.

\section{Text analysis}

Applying the text analysis on titles and abstracts, the WoS and Scopus database identified 31,710 terms and 11,454 terms, respectively. There were 145 terms in the WOS with the cut-off 100 times of appearance and 144 terms in the Scopus with the cut-off 31 times of appearance. Fig. S6a and $b$ shows the co-occurrence network of terms extracting from titles and abstracts. The size of a term indicating the number of its appearance in the titles and abstracts.
"Problematic Internet use" (Scopus, 1,446 times of appearance), and "addiction" (WOS, 2,682 times of appearance), and "Internet addiction" (WOS, 1,842 times of appearance) were three central nodes. Four main clusters (four different colors) in two databases could be identified (see Fig. S6a and b):

Theme 1. The blue cluster (WOS) and the red one (Scopus) consist mainly of the co-comorbidity: Internet addiction was found to be associated with psychiatric comorbidity including ADHD, depressive disorder, social phobia, and hostility. Many studies confirmed the association between Internet addiction, and psychiatric illness (Caplan, 2007; Costa, Patrao, \& Machado, 2018; Ko et al., 2012; Özdemir, Kuzucu, \& Ak, 2014; Shapira, Goldsmith, Keck, Khosla, \& McElroy, 2000; Yen, Ko, Yen, Wu, \& Yang, 2007). When treating people with Internet addiction, these disorders should be adequately assessed and treated at the same time.

Theme 2. The green cluster (WOS) and the yellow one (Scopus) cover the topic: questionnaires for assessing Internet addiction. All questionnaires were self-administered and ranging from 6 to 20 items on dimensional scales. The 
Table 1. Ten research topics classified by Latent Dirichlet allocation in WOS database

\begin{tabular}{|c|c|c|c|}
\hline $\begin{array}{l}\text { Rank by the } \\
\text { highest volume } \\
\text { last } 5 \text { years }\end{array}$ & Research topics & $N$ & Percent \\
\hline Topic 1 & $\begin{array}{l}\text { Smartphone } \\
\text { addiction }\end{array}$ & 107 & $4.70 \%$ \\
\hline Topic 2 & $\begin{array}{l}\text { Internet } \\
\text { addiction and } \\
\text { mental health } \\
\text { problems }\end{array}$ & 297 & $13.05 \%$ \\
\hline Topic 3 & $\begin{array}{c}\text { Internet } \\
\text { addiction and } \\
\text { depression } \\
\text { among University } \\
\text { Students }\end{array}$ & 385 & $17.00 \%$ \\
\hline Topic 4 & $\begin{array}{l}\text { Prevalence and } \\
\text { risk factors of } \\
\text { problematic } \\
\text { Internet use } \\
\text { among } \\
\text { adolescents }\end{array}$ & 215 & $9.45 \%$ \\
\hline Topic 5 & $\begin{array}{l}\text { Social media and } \\
\text { social network } \\
\text { games }\end{array}$ & 178 & $7.82 \%$ \\
\hline Topic 6 & $\begin{array}{l}\text { Validity and } \\
\text { Reliability Study } \\
\text { of the Internet } \\
\text { Addiction Test }\end{array}$ & 158 & $6.55 \%$ \\
\hline Topic 7 & $\begin{array}{l}\text { Brain Functional } \\
\text { Network in } \\
\text { Internet } \\
\text { Addiction or } \\
\text { Gaming disorder }\end{array}$ & 173 & $7.60 \%$ \\
\hline Topic 8 & $\begin{array}{c}\text { Internet } \\
\text { pornography } \\
\text { addiction and its } \\
\text { consequences }\end{array}$ & 255 & $11.20 \%$ \\
\hline Topic 9 & $\begin{array}{l}\text { Treatment } \\
\text { Interventions for } \\
\text { Internet } \\
\text { Addiction }\end{array}$ & 92 & $4.13 \%$ \\
\hline Topic 10 & $\begin{array}{c}\text { Gaming and } \\
\text { Gambling } \\
\text { disorder }\end{array}$ & 167 & $7.34 \%$ \\
\hline
\end{tabular}

Internet Addiction Test (Young, 1998) with 20 questions was most frequently used. For gaming disorder, the Assessment of Internet, and Computer Game Addiction (AICA-S), a 14-item self-report scale was frequently used to assess computer game addiction.

Theme 3. The red cluster (WOS) and the blue one (Scopus) mentioned the impact of electronic divides overuse could cause to the youth. It can be seen that research of treatment focused on the Scopus database. Specific psychological therapies, such as social support, counseling, and cognitive behavior therapy were found to help young people to overcome addiction to electronic devices and the Internet as well as feelings of loneliness (Mak et al., 2014; Schimmenti, Passanisi, Gervasi, Manzella, \& Fama, 2014). A strong family relationship was found to be an excellent method to prevent Internet addiction (Yu \& Shek, 2013). School-based support was required to support adolescents overcoming negative feelings (Özdemir et al., 2014). Another theme was psychoeducation to teach students to use the Internet effectively and supervise the time they spent online $(\mathrm{Li}$, Zhang, Lu, Zhang, \& Wang, 2014).

Theme 4. The yellow cluster (WOS) and the green one (Scopus) consist of the subjects of the papers: "adolescents", "high school student", "student". Besides, the difference in using the Internet between two genders was mentioned. Male and female both use mobile phone, however, the purpose of using was quite different. Females used the mobile phone for social reasons meanwhile men used the mobile phone for business purposes. On one hand, two risk factors for Internet addiction were male gender and social factor (Müller, Glaesmer, Brähler, Woelfling, \& Beutel, 2014; Yen et al., 2007). On the other hand, some studies show that young women tend to have a problem with Internet addiction (Derbyshire et al., 2013).

\section{Topic modeling using Latent Dirichlet allocation (LDA)}

Using LDA for text analysis in the titles and abstracts, we classified ten research topics in the WOS dataset (Table 1) and Scopus dataset (Table 2). In WOS dataset, topics with the highest number of publications were "Internet addiction and depression among University Students" $(n=385)$, "Internet addiction and mental health problem" $(n=297)$, and "Internet pornography addiction and its consequences" $(n=255)$. In Scopus dataset, "Internet addiction in adolescents and students: Prevalence and risk factors" ( $n=$ 116), "Problematic Internet use and mental health problems" ( $n=71)$, "PIU and psychological effects among students" ( $n=68)$. Both datasets show that the concern of the scientific community has been the effect of PIU on mental health, especially among students. Both WOS and Scopus share the same results when confirming that "Smartphone addiction" and the mental health illness affected by Internet addiction received the highest attention in the scientific community in the last five years (Figs. 5 and 6). Moreover, we provided 25 most cited papers in each database, which showed the highest attention of the researcher (Tables S5 and S6 Supplementary). The top three highest citation papers shared the same content with our research topics. The first and second publications in WOS focused on a framework for the development of cognitive-behavioral interventions for PIU (Caplan, 2002; Davis, 2001). The other papers reported the relations of PIU and com-morbidities (Kardefelt-Winther, 2014b; Shapira et al., 2000), theoretical development for PIU (Kardefelt-Winther, 2014a).

\section{DISCUSSION}

To the best of our knowledge, this study can be considered the first comprehensive and global bibliometric analysis on the excessive use of electronic devices and the Internet. Our 
Table 2. Ten research topics classified by Latent Dirichlet allocation in Scopus database

\begin{tabular}{|c|c|c|c|}
\hline $\begin{array}{l}\text { Rank by the } \\
\text { highest volume } \\
\text { last } 5 \text { years }\end{array}$ & Research topics & $N$ & Percent \\
\hline Topic 1 & $\begin{array}{l}\text { Smartphone } \\
\text { addiction in } \\
\text { workplace }\end{array}$ & 39 & $6.50 \%$ \\
\hline Topic 2 & $\begin{array}{l}\text { Parental Control } \\
\text { and Adolescent } \\
\text { Internet } \\
\text { Addiction }\end{array}$ & 19 & $3.17 \%$ \\
\hline Topic 3 & $\begin{array}{c}\text { PIU and } \\
\text { psychological } \\
\text { effects among } \\
\text { students }\end{array}$ & 68 & $11.33 \%$ \\
\hline Topic 4 & $\begin{array}{c}\text { Treatment of } \\
\text { Internet } \\
\text { addiction }\end{array}$ & 62 & $10.33 \%$ \\
\hline Topic 5 & $\begin{array}{l}\text { Problematic } \\
\text { Internet use and } \\
\text { mental health } \\
\text { problems }\end{array}$ & 71 & $11.83 \%$ \\
\hline Topic 6 & $\begin{array}{c}\text { Internet } \\
\text { Addiction, } \\
\text { Pathological } \\
\text { Gambling and } \\
\text { Psychiatric } \\
\text { Comorbidity } \\
\text { among } \\
\text { Adolescents }\end{array}$ & 61 & $10.17 \%$ \\
\hline Topic 7 & $\begin{array}{c}\text { Internet } \\
\text { addiction in } \\
\text { adolescents and } \\
\text { students: } \\
\text { Prevalence and } \\
\text { risk factors }\end{array}$ & 116 & $19.33 \%$ \\
\hline Topic 8 & $\begin{array}{l}\text { Online Social } \\
\text { Gaming and } \\
\text { Social } \\
\text { Networking Sites }\end{array}$ & 28 & $4.67 \%$ \\
\hline Topic 9 & $\begin{array}{l}\text { Psychometric } \\
\text { Properties of the } \\
\text { Problematic } \\
\text { Internet Use } \\
\text { Questionnaire }\end{array}$ & 43 & $7.17 \%$ \\
\hline Topic 10 & $\begin{array}{l}\text { Smartphone and } \\
\text { brain activity }\end{array}$ & 37 & $6.17 \%$ \\
\hline
\end{tabular}

findings showed that there had been a steady increase in the number of publications and citations in this area from 1971 to 2017. Although the number of papers eligible to be selected for further analysis in WOS database was three times that in Scopus database, both datasets displayed the same trend in the development of scientific research papers in PIU. First, both datasets confirmed that the US was the leading country in this area, yet there was an emergence of publications from Asian countries. Secondly, keyword and text analysis found that excessive use of electronic devices and the Internet mainly affected young people and led to psychiatric comorbidity. Various questionnaire assessments were developed to assess excessive use of electronic devices and the Internet as well as the mainstay of treatment is psychological intervention. Finally, there were limited publications looking into intervention or treatment for excessive use of electronic devices and the Internet.

Some of the global collaborations on excessive use of electronic devices and the Internet occurred among the following countries/regions: The United States, China, South Korea, and Taiwan. The presence of various Asian countries as major contributors for publication in this area reflected the growing concern of Asian society when facing the healthcare crisis associated with "Internet addiction" and excessive use of electronic devices. The excessive use of electronic devices and Internet has been considered a common problem in Vietnam, China, Taiwan, Hong Kong, and South Korea (Tran et al., 2017). To combat the rising prevalence of excessive use of electronic devices and the Internet in Asia, we call for new health policies and programs. Several Asian countries have established control and prevention measures. China, for instance, has applied tighter control on the Internet café and launched an anti-addiction program (Vondráčková \& Gabrhelík, 2016), while South Korea has established a systematic approach program "Hospital + School + Counseling Center" for treating people with PIU (Koo, Wati, Lee, \& Oh, 2011). Taiwan has revised the "Child, and Youth Welfare, and Protection Act" which requires the parents to pay a penalty of 1595 USD if their children become sick as a result of excessive use of electronic devices and Internet (Interior \& Taiwan China, 2012).

Our analysis of text mining (titles and abstracts only) and the visualization of titles and abstracts identified the concerns on "comorbidities" associated with excessive Internet uses. By using LDA, we found that the number of publications focuses on the relationship between PIU and psychiatric is increasing (Table 1 and 2). PIU can be a reason leading to psychosocial issues, such as depression (Stetina, Kothgassner, Lehenbauer, \& Kryspin-Exner, 2011), anxiety and loneliness (Schulz, Bergen, Schuhmann, \& Hoyer, 2017), or even suicide (Durkee, Hadlaczky, Westerlund, \& Carli, 2011). Most of the studies, however, were cross-sectional, such that confirmation on a causal relationship between PIU and mental health problems should be the aim of future researches (de Vries \& Nakamae, 2018). Moreover, the number of papers discussing treatments of PIU (4.13\% of the total number of publications in WOS dataset, $10.33 \%$ in Scopus dataset) was relatively small compared with other topics. In terms of available treatment, both databases mentioned non-medication therapy including cognitivebehavioral therapy (Young, 2007), family therapy (Zhong et al., 2011), self-discovery camp (Sakuma et al., 2017), Mindfulness-Oriented Recovery (W. Li et al., 2017) and pharmacotherapy. Although previous publications suggested the use of social support, counseling, or cognitive behavior therapy to treat excessive use of electronic devices and Internet, the efficiency of psychological interventions has not been well-discussed. Notably, there has been a lack of studies 


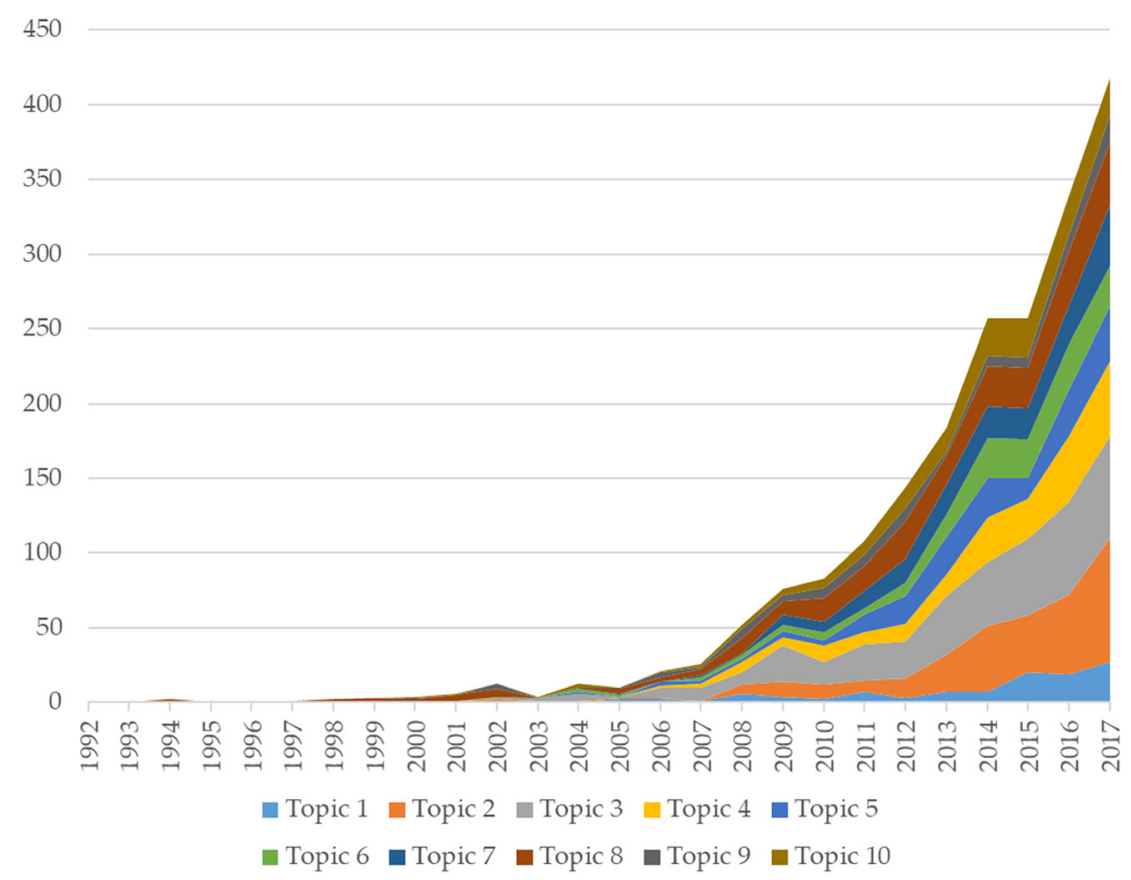

Fig. 5. Changes in research topics development in WOS

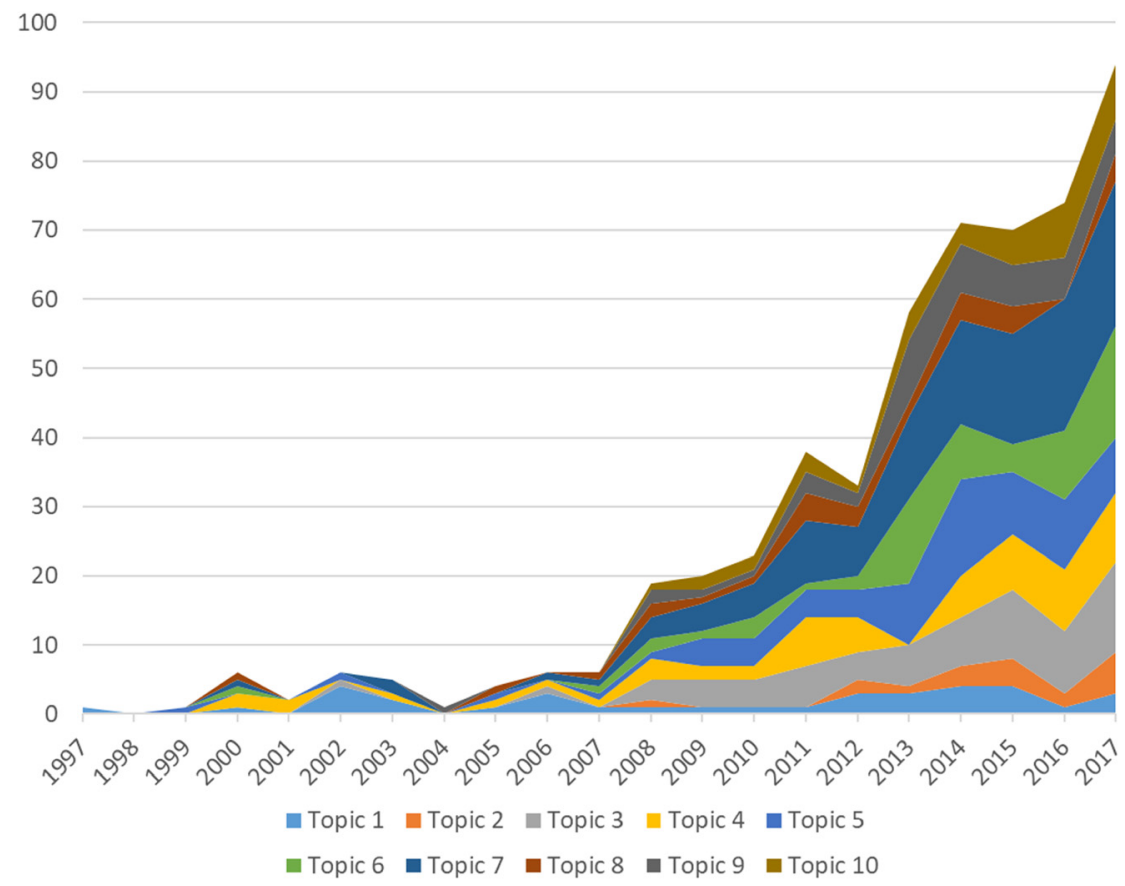

Fig. 6. Changes in research topics development in Scopus

focusing on pharmacological treatments for excessive use of the Internet and electronic devices. In both datasets, there were only three papers mentioned medication treatment. Further research thus may take the direction of evaluating the therapeutic effect of positivity which leads to a linear decrease in general distress and an indirect decrease in Internet addiction.

This bibliometric study has several limitations. Firstly, we were unable to present a "universal" definition or classification of excessive use of electronic devices and Internet. In fact, the debate on the definition and diagnostic criteria of excessive use or addiction to electronic devices and Internet will possibly continue to go on worldwide. While some mental health practitioners and researchers considered PIU as a symptom of a primary psychiatric disorder such as anxiety or depression (Ko et al., 2012), others classified PIU as an impulse control disorder. Nevertheless, there is a growing consensus that PIU is 
considered to be a form of addiction (Grant, Potenza, Weinstein, \& Gorelick, 2010). Secondly, we excluded some document types such as government documents, books or book chapters, and letters to editors and kept only articles and reviews, that may affect the result. Finally, the exclusion of non-English articles might lead to selection bias and made the number of publications of English-speaking countries was more than that of Asia or Africa ones.

\section{CONCLUSION}

In conclusion, this study presents a comprehensive overview of global research trends and development on the excessive use of electronic devices and Internet. Furthermore, it highlights the need for increasing global awareness about the effects of addiction to electronic devices and Internet. The findings of this study will help researchers and health authorities to formulate new research strategies and policies respectively.

Funding sources: No declared.

Authors' contribution: Conceptualization, Bach Xuan Tran, Giang Thu Vu and Carl A. Latkin; Data curation, Giang Hai Ha, Chi Linh Hoang, Cuong Tat Nguyen and Cyrus S.H. Ho; Formal analysis, Bach Xuan Tran, Giang Hai Ha, Carl A. Latkin and Roger C.M. Ho; Funding acquisition, Son Hoang Nguyen and Cyrus S.H. Ho; Investigation, Chi Linh Hoang and Roger C.M. Ho; Methodology, Bach Xuan Tran, Giang Hai Ha, Giang Thu Vu and Cuong Tat Nguyen; Project administration, Bach Xuan Tran, Son Hoang Nguyen and Roger C.M. Ho; Resources, Giang Hai Ha and Carl A. Latkin; Software, Giang Thu Vu, Chi Linh Hoang, Cyrus S.H. Ho and Roger C.M. Ho; Supervision, Bach Xuan Tran, Cuong Tat Nguyen and Carl A. Latkin; Validation, Bach Xuan Tran, Giang Thu Vu, Chi Linh Hoang, Son Hoang Nguyen and Cyrus S.H. Ho; Visualization, Giang Hai Ha and Roger C.M. Ho; Writing - original draft, Bach Xuan Tran, Giang Hai Ha, Giang Thu Vu, Chi Linh Hoang, Son Hoang Nguyen, Cuong Tat Nguyen, Carl A. Latkin, Cyrus S.H. Ho and Roger C.M. Ho; Writing - review \& editing, Bach Xuan Tran, Giang Hai Ha, Giang Thu Vu, Chi Linh Hoang, Son Hoang Nguyen, Cuong Tat Nguyen, Carl A. Latkin, Cyrus S.H. Ho and Roger C.M. Ho.

Conflict of interest: The authors declare no conflict of interest.

\section{REFERENCES}

Aarseth, E., Bean, A. M., Boonen, H., Colder Carras, M., Coulson, M., Das, D., et al. (2017). Scholars' open debate paper on the world health organization ICD-11 gaming disorder proposal.
The Journal of Behavioral Addictions, 6(3), 267-270. https:// doi.org/10.1556/2006.5.2016.088.

Anderson, E. L., Steen, E., \& Stavropoulos, V. (2017). Internet use and problematic internet use: A systematic review of longitudinal research trends in adolescence and emergent adulthood. International Journal of Adolescence and Youth, 22(4), 430454.

Aria, M., \& Cuccurullo, C. (2017). Bibliometrix: An R-tool for comprehensive science mapping analysis. Journal of Informetrics, 11(4), 959-975. https://doi.org/10.1016/j.joi.2017.08.007.

Bakken, I. J., Wenzel, H. G., Gotestam, K. G., Johansson, A., \& Oren, A. (2009). Internet addiction among Norwegian adults: A stratified probability sample study. Scandinavian Journal of Psychology, 50(2), 121-127. https://doi.org/10.1111/j.14679450.2008.00685.x.

Billieux, J., Van der Linden, M., Achab, S., Khazaal, Y., Paraskevopoulos, L., Zullino, D., et al. (2013). Why do you play world of warcraft? An in-depth exploration of self-reported motivations to play online and in-game behaviours in the virtual world of Azeroth. Computers in Human Behavior, 29(1), 103-109. https://doi.org/10.1016/j.chb.2012.07.021.

Black, D. W., Belsare, G., \& Schlosser, S. (1999). Clinical features, psychiatric comorbidity, and health-related quality of life in persons reporting compulsive computer use behavior. Journal of Clinical Psychiatry, 60(12), 839-844.

Breslau, J., Aharoni, E., Pedersen, E. R., \& Miller, L. L. (2015). A review of research on problematic Internet use and well-being: With recommendations for the US Air force. Rand Health Quarterly, 5(1), 20.

Caplan, S. E. (2002). Problematic internet use and psychosocial well-being: Development of a theory-based cognitive-behavioral measurement instrument. Computers in Human Behavior, 18(5), 553-575.

Caplan, S. E. (2007). Relations among loneliness, social anxiety, and problematic internet use. CyberPsychology and Behavior, 10(2), 234-242. https://doi.org/10.1089/cpb.2006.9963.

Chen, C., Zare, A., Trinh, H. N., Omotara, G. O., Cobb, J. T., \& Lagaunne, T. A. (2017). Partial membership latent dirichlet allocation for soft image segmentation. IEEE Transactions on Image Processing, 26(12), 5590-5602.

Cheng, C., \& Li, A. Y. (2014). Internet addiction prevalence and quality of (real) life: A meta-analysis of 31 nations across seven world regions. Cyberpsychology, Behavior, and Social Networking, 17(12), 755-760. https://doi.org/10.1089/cyber.2014.0317.

Chou, W. P., Ko, C. H., Kaufman, E. A., Crowell, S. E., Hsiao, R. C., Wang, P. W., et al. (2015). Association of stress coping strategies with internet addiction in college students: The moderating effect of depression. Comprehensive Psychiatry, 62, 2733. https://doi.org/10.1016/j.comppsych.2015.06.004.

Costa, R. M., Patrao, I., \& Machado, M. (2018). Problematic internet use and feelings of loneliness. International Journal of Psychiatry in Clinical Practice, 23, 1-3. https://doi.org/10.1080/ 13651501.2018.1539180.

Dang, A. K., Nathan, N., Le, Q. N. H., Nguyen, L. H., Nguyen, H. L. T., Nguyen, C. T., et al. (2018). Associations between internet addiction and physical activity among Vietnamese youths and adolescents. Children and Youth Services Review, 93, 36-40. https://doi.org/10.1016/j.childyouth.2018.06.030. 
Davis, R. A. (2001). A cognitive-behavioral model of pathological internet use. Computers in Human Behavior, 17(2), 187-195. https://doi.org/10.1016/S0747-5632(00)00041-8.

de Vries, H. T., \& Nakamae, T. (2018). Problematic internet use and psychiatric co-morbidity in a population of Japanese adult psychiatric patients. BMC Psychiatry, 18(1), 9. https://doi.org/ 10.1186/s12888-018-1588-z.

Deetjen, U., \& Powell, J. A. (2016). Internet use and health: Connecting secondary data through spatial microsimulation. Digit Health, 2. https://doi.org/10.1177/2055207616666588.

Derbyshire, K. L., Lust, K. A., Schreiber, L. R., Odlaug, B. L., Christenson, G. A., Golden, D. J., et al. (2013). Problematic internet use and associated risks in a college sample. Comprehensive Psychiatry, 54(5), 415-422. https://doi.org/10.1016/j. comppsych.2012.11.003.

Dullur, P., \& Starcevic, V. (2018). Internet gaming disorder does not qualify as a mental disorder. Australian and New Zealand Journal of Psychiatry, 52(2), 110-111. https://doi.org/10.1177/ 0004867417741554.

Durkee, T., Hadlaczky, G., Westerlund, M., \& Carli, V. (2011). Internet pathways in suicidality: A review of the evidence. International Journal of Environmental Research and Public Health, 8(10), 3938-3952.

Durkee, T., Kaess, M., Carli, V., Parzer, P., Wasserman, C., Floderus, B., et al. (2012). Prevalence of pathological internet use among adolescents in Europe: Demographic and social factors. Addiction (Abingdon, England), 107(12), 2210-2222. https:// doi.org/10.1111/j.1360-0443.2012.03946.x.

EBSCO. PsycINFO. Retrieved from https://www.ebsco.com/ products/research-databases/psycinfo.

El Asam, A., Samara, M., \& Terry, P. (2019). Problematic internet use and mental health among British children and adolescents. Addictive Behaviors, 90, 428-436. https://doi.org/10.1016/j. addbeh.2018.09.007.

Fauth-Bühler, M., Mann, K., \& Potenza, M. N. (2017). Pathological gambling: A review of the neurobiological evidence relevant for its classification as an addictive disorder. Addiction Biology, 22(4), 885-897.

Grant, J. E., Potenza, M. N., Weinstein, A., \& Gorelick, D. A. (2010). Introduction to behavioral addictions. The American Journal of Drug and Alcohol Abuse, 36(5), 233-241. https://doi. org/10.3109/00952990.2010.491884.

Griffiths, M., Király, O., Pontes, H., \& Demetrovics, Z. (2015). An overview of problematic gaming. Mental health in the digital age: Grave dangers, great promise (pp. 27-45).

Griffiths, M. D. (1995). Technological addictions. Clinical Psychology Forum, 76, 14-19.

Griffiths, M. D. (1996). Gambling on the internet: A brief note. Journal of Gambling Studies, 12, 471-473.

Griffiths, M. D., van Rooij, A. J., Kardefelt-Winther, D., Starcevic, V., Király, O., Pallesen, S., et al. (2016). Working towards an international consensus on criteria for assessing internet gaming disorder: A critical commentary on Petry et al. (2014). Addiction (Abingdon, England), 111(1), 167-175. https://doi. org/10.1111/add.13057.

Guillot, C. R., Bello, M. S., Tsai, J. Y., Huh, J., Leventhal, A. M., \& Sussman, S. (2016). Longitudinal associations between anhedonia and internet-related addictive behaviors in emerging adults. Computers in Human Behavior, 62, 475-479. https:// doi.org/10.1016/j.chb.2016.04.019.

Guz, A. N., \& Rushchitsky, J. J. (2009). Scopus: A system for the evaluation of scientific journals. International Applied Mechanics, 45, 351.

Ha, J. H., Yoo, H. J., Cho, I. H., Chin, B., Shin, D., \& Kim, J. H. (2006). Psychiatric comorbidity assessed in Korean children and adolescents who screen positive for internet addiction. Journal of Clinical Psychiatry, 67(5), 821-826.

Harris, K. M., Starcevic, V., Ma, J., Zhang, W., \& Aboujaoude, E. (2017). Suicidality, psychopathology, and the internet: Online time vs. online behaviors. Psychiatry Research, 255, 341-346. https://doi.org/10.1016/j.psychres.2017.06.012.

Interior, M. o. t., \& Taiwan China. (2012). The protection of children and youths welfare and rights act. Retrieved from: https://www. moi.gov.tw/english/english_law/law_detail.aspx?sn=157.

Jelodar, H., Wang, Y., Yuan, C., Feng, X., Jiang, X., Li, Y., et al. (2019). Latent dirichlet allocation (LDA) and topic modeling: Models, applications, a survey. Multimedia Tools and Applications, 78(11), 15169-15211.

Jung, Y. E., Leventhal, B., Kim, Y. S., Park, T. W., Lee, S. H., Lee, M., et al. (2014). Cyberbullying, problematic internet use, and psychopathologic symptoms among Korean youth. Yonsei Medical Journal, 55(3), 826-830. https://doi.org/10.3349/ymj. 2014.55.3.826.

Kardefelt-Winther, D. (2014a). A conceptual and methodological critique of internet addiction research: Towards a model of compensatory internet use. Computers in Human Behavior, 31, 351-354. https://doi.org/10.1016/j.chb.2013.10.059.

Kardefelt-Winther, D. (2014b). A conceptual and methodological critique of internet addiction research: Towards a model of compensatory internet use. Computers in Human Behavior, 31, 351-354. https://doi.org/10.1016/j.chb.2013.10.059.

King, D. L., Delfabbro, P. H., Doh, Y. Y., Wu, A. M. S., Kuss, D. J., Pallesen, S., et al. (2018a). Policy and prevention approaches for disordered and hazardous gaming and internet use: An international perspective. Prevention Science, 19(2), 233-249. https://doi.org/10.1007/s11121-017-0813-1.

King, D. L., Delfabbro, P. H., Potenza, M. N., Demetrovics, Z., Billieux, J., \& Brand, M. (2018b). Internet gaming disorder should qualify as a mental disorder. Australian and New Zealand Journal of Psychiatry, 52(7), 615-617. https://doi.org/10. 1177/0004867418771189.

Kiraly, O., \& Demetrovics, Z. (2017). Inclusion of Gaming Disorder in ICD has more advantages than disadvantages. The Journal of Behavioral Addictions, 6(3), 280-284. https://doi.org/10.1556/ 2006.6.2017.046.

Ko, C. H., Liu, G. C., Hsiao, S., Yen, J. Y., Yang, M. J., Lin, W. C., et al. (2009). Brain activities associated with gaming urge of online gaming addiction. Journal of Psychiatric Research, 43(7), 739-747. https://doi.org/10.1016/j.jpsychires.2008.09.012.

Ko, C. H., Yen, C. F., Long, C. Y., Chen, C. S., Huang, T. H., \& Yen, J. Y. (2014). The association between premenstrual dysphoric disorder and internet use disorder. Women \& Health, 54(3), 245-261. https://doi.org/10.1080/03630242.2014.883661.

Ko, C. H., Yen, J. Y., Yen, C. F., Chen, C. C., Yen, C. N., \& Chen, S. H. (2005). Screening for internet addiction: An empirical study on cut-off points for the chen internet addiction scale. The 
Kaohsiung Journal of Medical Sciences, 21(12), 545-551. https://doi.org/10.1016/S1607-551X(09)70206-2.

Ko, C. H., Yen, J. Y., Yen, C. F., Chen, C. S., \& Chen, C. C. (2012). The association between internet addiction and psychiatric disorder: A review of the literature. European Psychiatry, 27(1), 1-8. https://doi.org/10.1016/j.eurpsy.2010.04.011.

Kojima, R., Sato, M., Akiyama, Y., Shinohara, R., Mizorogi, S., Suzuki, K., et al. (2019). Problematic Internet use and its associations with health-related symptoms and lifestyle habits among rural Japanese adolescents. Psychiatry and Clinical Neurosciences, 73(1), 20-26. https://doi.org/10.1111/pcn.12791.

Kokol, P., \& Vošner, H. B. (2018). Discrepancies among Scopus, Web of Science, and PubMed coverage of funding information in medical journal articles. Journal of the Medical Library Association, 106(1), 81-86. https://doi.org/10.5195/jmla.2018.181.

Koo, C., Wati, Y., Lee, C. C., \& Oh, H. Y. (2011). Internet-Addicted kids and South Korean government efforts: Boot-camp case. Cyberpsychology, Behavior, and Social Networking, 14(6), 391394. https://doi.org/10.1089/cyber.2009.0331.

Kuss, D. J., \& Lopez-Fernandez, O. (2016). Internet addiction and problematic internet use: A systematic review of clinical research. World Journal of Psychiatry, 6(1), 143.

Lee, J. Y., Chung, Y. C., Song, J. H., Lee, Y. H., Kim, J. M., Shin, I. S., et al. (2018). Contribution of stress and coping strategies to problematic internet use in patients with schizophrenia spectrum disorders. Comprehensive Psychiatry, 87, 89-94. https:// doi.org/10.1016/j.comppsych.2018.09.007.

Levine, S., \& Stephens, R. (1971). Games addicts play. Psychiatric Quarterly, 45(4), 582-592. https://doi.org/10.1007/bf01563219.

Li, W., Garland, E. L., McGovern, P., O’Brien, J. E., Tronnier, C., \& Howard, M. O. (2017). Mindfulness-oriented recovery enhancement for internet gaming disorder in US adults: A stage I randomized controlled trial. Psychology of Addictive Behaviors, 31(4), 393.

Li, Y., Rapkin, B., Atkinson, T. M., Schofield, E., \& Bochner, B. H. (2019). Leveraging Latent Dirichlet Allocation in processing free-text personal goals among patients undergoing bladder cancer surgery. Quality of Life Research, 28(6), 1441-1455.

Li, Y., Zhang, X., Lu, F., Zhang, Q., \& Wang, Y. (2014). Internet addiction among elementary and middle school students in China: A nationally representative sample study. Cyberpsychology, Behavior, and Social Networking, 17(2), 111-116. https://doi.org/10.1089/cyber.2012.0482.

Lin, I. H., Ko, C. H., Chang, Y. P., Liu, T. L., Wang, P. W., Lin, H. C., et al. (2014). The association between suicidality and Internet addiction and activities in Taiwanese adolescents. Comprehensive Psychiatry, 55(3), 504-510. https://doi.org/10. 1016/j.comppsych.2013.11.012.

Lu, W. H., Lee, K. H., Ko, C. H., Hsiao, R. C., Hu, H. F., \& Yen, C. F. (2017). Relationship between borderline personality symptoms and internet addiction: The mediating effects of mental health problems. The Journal of Behavioral Addictions, 6(3), 434-441. https://doi.org/10.1556/2006.6.2017.053.

Mak, K. K., Lai, C. M., Watanabe, H., Kim, D. I., Bahar, N., Ramos, M., et al. (2014). Epidemiology of internet behaviors and addiction among adolescents in six Asian countries. Cyberpsychology, Behavior, and Social Networking, 17(11), 720-728. https://doi.org/10.1089/cyber.2014.0139.
Müller, K. W., Glaesmer, H., Brähler, E., Woelfling, K., \& Beutel, M. E. (2014). Prevalence of internet addiction in the general population: Results from a German population-based survey. Behaviour \& Information Technology, 33(7), 757-766. https:// doi.org/10.1080/0144929X.2013.810778.

Mythily, S., Qiu, S., \& Winslow, M. (2008). Prevalence and correlates of excessive internet use among youth in Singapore. Annals Academy of Medicine Singapore, 37(1), 9-14.

Opthof, T., \& Wilde, A. A. (2009). The hirsch-index: A simple, new tool for the assessment of scientific output of individual scientists: The case of Dutch professors in clinical cardiology. Netherlands Heart Journal, 17(4), 145-154.

Özdemir, Y., Kuzucu, Y., \& Ak, Ş. (2014). Depression, loneliness and internet addiction: How important is low self-control? Computers in Human Behavior, 34, 284-290. https://doi.org/ 10.1016/j.chb.2014.02.009.

Park, M. H., Park, S., Jung, K. I., Kim, J. I., Cho, S. C., \& Kim, B. N. (2018). Moderating effects of depressive symptoms on the relationship between problematic use of the internet and sleep problems in Korean adolescents. BMC Psychiatry, 18(1), 280. https://doi.org/10.1186/s12888-018-1865-x.

Perianes-Rodriguez, A., Waltman, L., \& van Eck, N. J. (2016). Constructing bibliometric networks: A comparison between full and fractional counting. Journal of Informetrics, 10(4), 1178-1195.

Rennert, L., Denis, C., Peer, K., Lynch, K. G., Gelernter, J., \& Kranzler, H. R. (2014). DSM-5 gambling disorder: Prevalence and characteristics in a substance use disorder sample. Experimental and Clinical Psychopharmacology, 22(1), 50-56. https://doi.org/10.1037/a0034518.

Sakuma, H., Mihara, S., Nakayama, H., Miura, K., Kitayuguchi, T., Maezono, M., et al. (2017). Treatment with the self-discovery camp (SDiC) improves internet gaming disorder. Addictive Behaviors, 64, 357-362. https://doi.org/10.1016/j.addbeh.2016.06. 013 .

Schimmenti, A., Passanisi, A., Gervasi, A. M., Manzella, S., \& Fama, F. I. (2014). Insecure attachment attitudes in the onset of problematic internet use among late adolescents. Child Psychiatry and Human Development, 45(5), 588-595. https://doi. org/10.1007/s10578-013-0428-0.

Schulz, A., Bergen, E., Schuhmann, P., \& Hoyer, J. (2017). Social anxiety and loneliness in adults who solicit minors online. Sexual Abuse, 29(6), 519-540.

Schwarz, C. (2018). ldagibbs: A command for topic modeling in Stata using latent Dirichlet allocation. The Stata Journal, 18(1), 101-117.

Shapira, N. A., Goldsmith, T. D., Keck, P. E., , Jr., Khosla, U. M., \& McElroy, S. L. (2000). Psychiatric features of individuals with problematic internet use. Journal of Affective Disorders, 57(13), 267-272. https://doi.org/10.1016/s0165-0327(99)00107-x.

Shapira, N. A., Lessig, M. C., Goldsmith, T. D., Szabo, S. T., Lazoritz, M., Gold, M. S., et al. (2003). Problematic internet use: Proposed classification and diagnostic criteria. Depression and Anxiety, 17(4), 207-216. https://doi.org/10.1002/da. 10094.

Sherer, K. (1997). College life on-line: Healthy and unhealthy internet use. Journal of College Student Development, 655-665.

Statista. Statistics and market data about the internet. Retrieved from: https://www.statista.com/markets/424/internet/. 
Stetina, B. U., Kothgassner, O. D., Lehenbauer, M., \& Kryspin-Exner, I. (2011). Beyond the fascination of online-games: Probing addictive behavior and depression in the world of online-gaming. Computers in Human Behavior, 27(1), 473-479.

Tran, B. X., Huong, L. T., Hinh, N. D., Nguyen, L. H., Le, B. N., Nong, V. M., et al. (2017). A study on the influence of internet addiction and online interpersonal influences on health-related quality of life in young Vietnamese. BMC Public Health, 17(1), 138. https://doi.org/10.1186/s12889-016-3983-z.

Valle, D., Albuquerque, P., Zhao, Q., Barberan, A., \& Fletcher , Jr, R. J. (2018). Extending the latent dirichlet allocation model to presence/absence data: A case study on North American breeding birds and biogeographical shifts expected from climate change. Global Change Biology, 24(11), 5560-5572.

van Eck, N. J., \& Waltman, L. (2011). Text mining and visualization using VOSviewer. ISSI Newsletter, 7.

Van Eck, N. J., \& Waltman, L. (2014). Visualizing bibliometric networks. In Measuring scholarly impact (pp. 285-320). Springer.

van Eck, N. J., Waltman, L., Dekker, R., \& van den Berg, J. (2010). A comparison of two techniques for bibliometric mapping: Multidimensional scaling and VOS. Journal of the American Society for Information Science and Technology, 61(12), 24052416. https://doi.org/10.1002/asi.21421.

Vondráčková, P., \& Gabrhelík, R. (2016). Prevention of internet addiction: A systematic review. The Journal of Behavioral Addictions, 5(4), 568-579. https://doi.org/10.1556/2006.5.2016.085.

Wang, C. Y., Wu, Y. C., Su, C. H., Lin, P. C., Ko, C. H., \& Yen, J. Y. (2017). Association between internet gaming disorder and generalized anxiety disorder. The Journal of Behavioral Addictions, 6(4), 564-571. https://doi.org/10.1556/2006.6.2017.088.

Wang, Y., Joo, S., \& Lu, K. (2014). Exploring topics in the field of data science by analyzing wikipedia documents: A preliminary result. Proceedings of the American Society for Information Science and Technology, 51(1), 1-4. https://doi.org/10.1002/ meet.2014.14505101116.

Wartberg, L., Brunner, R., Kriston, L., Durkee, T., Parzer, P., FischerWaldschmidt, G., et al. (2016). Psychopathological factors associated with problematic alcohol and problematic internet use in a sample of adolescents in Germany. Psychiatry Research, 240, 272-277. https://doi.org/10.1016/j.psychres.2016.04.057.

Wu, A. M. S., Chen, J. H., Tong, K. K., Yu, S., \& Lau, J. T. F. (2018). Prevalence and associated factors of internet gaming disorder among community dwelling adults in Macao, China. The Journal of Behavioral Addictions, 7(1), 62-69. https://doi.org/ 10.1556/2006.7.2018.12.

Yen, J. Y., Ko, C. H., Yen, C. F., Wu, H. Y., \& Yang, M. J. (2007). The comorbid psychiatric symptoms of internet addiction: Attention deficit and hyperactivity disorder (ADHD), depression, social phobia, and hostility. Journal of Adolescent Health, 41(1), 93-98. https://doi.org/10.1016/j.jadohealth.2007.02.002.

Yen, J. Y., Liu, T. L., Wang, P. W., Chen, C. S., Yen, C. F., \& Ko, C. H. (2017). Association between internet gaming disorder and adult attention deficit and hyperactivity disorder and their correlates: Impulsivity and hostility. Addictive Behaviors, 64, 308-313. https://doi.org/10.1016/j.addbeh.2016.04.024.

Young, K. (1999). Internet addiction: Symptoms, evaluation and treatment. Innovations in Clinical Practice: A Source Book, 17, $19-31$.

Young, K. S. (1996). Psychology of computer use: XL. Addictive use of the internet: A case that breaks the stereotype. Psychological Reports, 79(3 Pt 1), 899-902. https://doi.org/10.2466/pr0.1996.79.3.899.

Young, K. S. (1998). Caught in the Net: How to recognize the signs of internet addiction and a winning strategy for recovery: New York: Wiley.

Young, K. S. (2007). Cognitive behavior therapy with internet addicts: Treatment outcomes and implications. CyberPsychology and Behavior, 10(5), 671-679.

Yu, F., \& Hayes, B. E. (2018). Applying data analytics and visualization to assessing the research impact of the cancer cell biology (CCB) program at the university of North Carolina at chapel hill. Journal of eScience Librarianship, 7(1), 4.

Yu, L., \& Shek, D. T. (2013). Internet addiction in Hong Kong adolescents: A three-year longitudinal study. Journal of Pediatric and Adolescent Gynecology, 26(3 Suppl.), S10-S17. https://doi.org/10.1016/j.jpag.2013.03.010.

Zhang, M. W. B., Lim, R. B. C., Lee, C., \& Ho, R. C. M. (2018). Prevalence of internet addiction in medical students: A metaanalysis. Academic Psychiatry, 42(1), 88-93. https://doi.org/10. 1007/s40596-017-0794-1.

Zhang, M. W. B., Tran, B. X., Huong, L. T., Hinh, N. D., Nguyen, H. L. T., Tho, T. D., et al. (2017). Internet addiction and sleep quality among Vietnamese youths. Asian Journal of Psychiatry, 28, 15-20. https://doi.org/10.1016/j.ajp.2017.03.025.

Zhang, Y., Mei, S., Li, L., Chai, J., Li, J., \& Du, H. (2015). The relationship between impulsivity and internet addiction in Chinese college students: A moderated mediation analysis of meaning in life and self-esteem. PloS One, 10(7), e0131597. https://doi.org/10.1371/journal.pone.0131597.

Zhong, X., Zu, S., Sha, S., Tao, R., Zhao, C., Yang, F., et al. (2011). The effect of a family-based intervention model on internetaddicted Chinese adolescents. Social Behavior and Personality: An International Journal, 39(8), 1021-1034.

The Supplementary material for this article can be found at https://doi.org/10.1515/2006.2020.00031. 